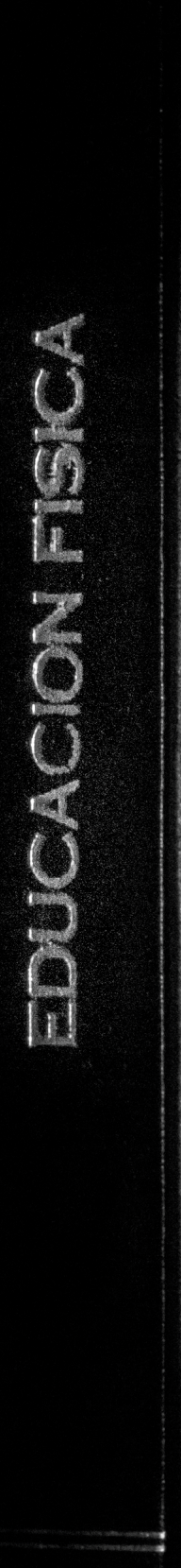

\title{
IBUCACIONFISICA
}

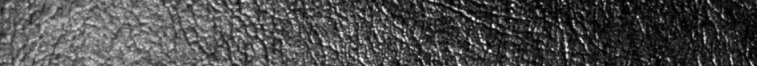

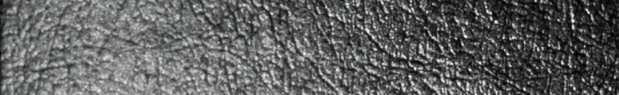

1.

$(x+1)=$

3.1.

Hor:

$x^{2}+y^{3}$

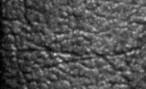




\section{La noción de cultura popular: interés de los debates entre los ochenta y noventa del siglo XX para reflexionar sobre la contemporaneidad}

\section{Artículo de reflexión}

\section{Manuel Kingman \\ Pontificia Universidad Católica del Ecuador makingman@puce.edu.ec}

Cómo citar este artículo: Kingman M. [2017]. La noción de cultura popular: interés de los debates entre los ochenta y noventa del siglo XX para reflexionar sobre la contemporaneidad, Calle14 revista de investigación en el campo del arte, 12[२2], 280-291

DOl: https://doi.org/10.14483/21450706.12359

\section{Resumen}

El presente artículo referencia teorías sobre la cultura popular ubicadas en las décadas del 80 y el 90 del siglo pasado, un periodo de reflexión pertinente y profunda en torno al término. Se visibiliza la complejidad de la noción de cultura popular, así como las distintas significaciones y sentidos que ha tenido el concepto. También se estudian ciertas entradas teóricas que son útiles para analizar la cultura popular. Se piensa en estos insumos teóricos como herramientas para reflexionar sobre las representaciones, diálogos y tensiones entre el arte contemporáneo y las manifestaciones estéticas populares.

\section{Palabras claves}

Cultura popular, arte contemporáneo, teoría cultural, antropología. 


\title{
The Notion of Popular Culture: The Importance of the Debates Between the 80 s and 90 s of the 20th Century to Reflect on Contemporaneity
}

\begin{abstract}
This article refers to theories about popular culture in the 80 s and 90 s of the past century, a period of pertinent and profound reflection on the term. It presents the complexity of the notion of popular culture, as well as the different meanings and uses the concept has had. It also analyzes certain theoretical inputs that are useful for analyzing popular culture. We think of these theoretical inputs as tools to reflect on the representations, dialogues and tensions between contemporary art and popular aesthetic manifestations.
\end{abstract}

\section{Keywords}

Popular culture, contemporary art, cultural theory, anthropology.

\section{La notion de culture populaire : intérêts des débats entre les années 80 et 90 du XXe siècle pour réfléchir sur la contemporanéité}

\section{Résumé}

Cet article se réfère à des théories sur la culture populaire dans les années 80 et 90 du siècle dernier, une période de réflexion pertinente et profonde sur le terme. II présente la complexité de la notion de culture populaire, ainsi que les différentes significations et usage du concept. II étudie également certains éléments théoriques utiles à l'analyse de la culture populaire. Nous pensons à ces apports théoriques comme outils pour réfléchir sur les représentations, les dialogues et les tensions entre l'art contemporain et les manifestations esthétiques populaires.

\section{Mots clés}

Culture populaire, art contemporain, théorie culturelle, anthropologie.

\section{A noção de cultura popular: interesses dos debates entre os 80 e 90 do século xx para reflexionar sobre a contemporaneidade}

\section{Resumo}

O presente artigo referência teorias sobre a cultura popular localizada nas décadas dos oitenta e o noventa do século passado, um período de reflexão pertinente e profunda em torno ao termo. Se visibiliza a complexidade da noção de cultura popular assim como as diferentes significações e sentidos que tem tido o conceito. Também se analisam certas entradas teóricas que são úteis para analisar a cultura popular. Se pensa nestes insumos teóricos como ferramentas para reflexionar sobre as representações, diálogos e tensões entre a arte contemporânea e as manifestações estéticas populares. 


\section{Palavras-chave}

Cultura popular, arte contemporânea, teoria cultural, antropologia.

\section{La noción de cultura popular interés debatekunape entre 80 y 90 siglo XX iuiarengapa contemporaniedadmanda.}

\section{Maillallachiska:}

Kai articulok referenciame teoriakuna cultura kaska decadape posagchunga y iskun chunga ialiska siglomanda, sug suma iuiarei entorno terminomanda. Kauarenme complejidad nocionpe cultura popularpe chasallata sug rigcha significación y sentido iukarka chi concepto. Chasallata analizare sug entradakuna teóricas valenkuna analizangapa cultura popular. luairenme kai insumo teóricos herramientasina iuiarengapa representacionkunamanda, rimai tensiones arte contemporaneanope y manifestación estéticas populares.

\section{Rimangapa Ministidukuna:}

Cultura popular, arte contemporáneo, teoría cultural, antropología.

\section{Introducción:}

Este artículo recoge entradas teóricas sobre la noción de cultura popular. Este relevamiento fue parte de la investigación sobre arte contemporáneo y cultura popular en el contexto de Quito y ubica discusiones de la década de los 80 y 90 . En la primera parte del ensayo se analiza la noción de cultura popular como un término complejo y problemático que ha tenido un gran número de significaciones; también se referencian algunos análisis antropológicos y de los estudios culturales sobre las dinámicas de la cultura popular. En la segunda parte se elabora un relevamiento de textos críticos sobre la circulación y puesta en escena de la cultura popular en circuitos intelectuales y artísticos. Aunque estas aproximaciones dan cuenta de un debate sucedido en las décadas del 80 y el 90, considero que este relevamiento es un aporte para pensar la relación entre arte y manifestaciones estéticas populares en la contemporaneidad. Los textos referenciados en este artículo fueron producidos en un periodo que tuvo al concepto de cultura popular como un elemento central, tanto en el debate amplio de las ciencias sociales, como en la antropología y los estudios culturales. Sería de interés contrastar estas teorías con discusiones más actualizadas. No obstante, ese no es el objetivo de este texto, sino más bien comparar los fundamentos del debate sobre la compleja noción de cultura popular.

\section{Sobre la complejidad de la noción de cultura popular}

\footnotetext{
Al hablar de cultura popular estamos describiendo un término complejo, cuya definición ha estado sujeta a distintos significados de acuerdo a su paso por variados procesos históricos y enunciados discursivos. Cultura popular ha sido usado por modernizadores, folcloristas, y artistas: aunque el uso de estas dos palabras ha sido diverso, nunca se ha llegado a un acuerdo definitivo
} 
[Salman, 1996: 3]. Es un término problemático que ha tenido muchas interpretaciones y conceptualizaciones teóricas contrapuestas. Esa gran cantidad de discusiones, concepciones y reflexiones podrían constituir un riesgo analítico, sin embargo, para reflexionar sobre la relación entre arte contemporáneo y contextos sociales, así como un repertorio de visualidades y sonoridades que se encuentran en el ámbito de lo cotidiano o en el espacio de lo subalterno. Soy de la opinión que cultura popular es el concepto más útil en ese empeño.

Es necesario partir de que la cultura popular es una construcción históricamente situada, es un término controversial que en su génesis como concepto teórico en el siglo XVIII en Europa [Burke, citado por Traube, 1996] tuvo relación con ideologías excluyentes que veían a lo popular como una negatividad que hay que controlar por el riesgo de desbordamiento. Paralelamente, y como la cara reversa de la misma moneda, esta concepción de lo popular también fue parte de una visión positivada de la cultura campesina, que sin embargo se encontraba romantizada y anclada en una valoración de las tradiciones. En ese entonces, lo contrario a la cultura popular era la cultura erudita o cultura de élite. Esta separación también estaba dada por una separación entre alta y baja cultura relacionada con un proceso de distanciamiento entre la cultura de las cortes (lo refinado) y los plebeyos (lo bárbaro, lo popular]. En un proceso histórico la cultura cortesana se diferencia del pueblo por medio del aprendizaje de hábitos civilizados que cada vez la separan más de la barbarie [Elias, 1986). Esta separación binaria entre lo culto y lo popular ha persistido a lo largo del tiempo y, como lo mantiene Ticio Escobar [2008], ha sido una de los presupuestos por medio de los cuales se crearía siglos después el concepto de arte moderno - como equivalente a lo refinado y como sinónimo de lo culto.

Antes de profundizar sobre los acercamientos al extenso concepto de cultura popular, hay que abordar de manera sucinta los modos como ha sido abordado lo popular desde las distintas disciplinas. La historia, los estudios literarios, la sociología y la antropología se han enfrentado a la disyuntiva de cómo encarar un vasto campo de estudio. Desde los años 60, estas ciencias sociales han impugnado la clasificación de la cultura entre lo elevado y lo popular [Mukerji y Chudson, 1991: 2-8). Así, en la década del 60 la historia se planteó hacer un trabajo histórico desde abajo, tratando de acercarse a la narrativa de los modos de vida de las clases populares a través de la búsqueda de otras fuentes a las presentes en los relatos oficiales. (Le Fevre, Braudel, Le Goff, Carlo Ginzburg].
Para entender la relación entre la alta y la baja cultura son importantes los aportes de Bourdieu ya que permiten ubicar las distinciones de la alta cultura como parte de procesos de estratificación social. Bourdieu estudia la relación de los consumos y el gusto con las clases sociales para evidenciar que se hacen presentes relaciones de jerarquía, subordinación y distinción entre varios estratos sociales [Mukerji y Chudson, 1991].

Otra línea de estudio está presente en los estudios culturales británicos [Stuart Hall, 1984, y Raymond Williams, 1997], donde, para acercarse a la cultura popular se ha repensado el marxismo a partir de la incorporación del término de hegemonía de Gramsci [Traube, 1996: 41].

En este punto cabe analizar la entrada a lo popular desde la antropología. Hay que recordar que, a diferencia de la sociología, que se concentra en el estudio de las problemáticas de las sociedades occidentales, la antropología nace como una ciencia para estudiar a las sociedades primitivas. Esto explica en parte el poco interés que tradicionalmente ha tenido la práctica antropológica en el entendimiento de las formas culturales populares contemporáneas o en la influencia que los medios masivos de comunicación han tenido en las culturas. [Mujkerji y Chudson, 1991: 18). La antropología ha tratado de entender otros puntos de vista del mundo a los hegemónicos, buscar otras miradas a las del capitalismo occidental y, al menos como intención, hacerlo desde los propios términos de los sujetos investigados. Estos esfuerzos muchas veces han sido infructuosos, otras veces han conllevado hacia una otrificación de lo no occidental. En todo caso, el acercamiento antropológico a la cultura permitió desafiar las nociones evolucionistas de cultura, ideas presentes en el espíritu de la ilustración que veía el camino marcado por Europa como un valor universal [Crehan, 2002: 45]. Dentro del relativismo cultural, la principal función de la antropología ha sido la de entender las formas de vida tradicionales, es decir, las culturas primitivas [Mujkerji y Chudson, 1991: 18] como todos delimitados que podían ser entendidos en función de sus propias tradiciones culturales $y$, de alguna manera, aisladas de los contextos políticos mundiales (Crehan, 2002). Para Mujkerji y Chudson, es el estructuralismo de Levi-Strauss el que comienza a afectar el entendimiento de la práctica antropológica como una disciplina enfocada al estudio de culturas delimitadas. Al introducir a la lengua como una parte estructurada y estructurante de la cultura, de alguna manera desafía la idea de que las culturas son totalidades puras: para Levi-Strauss todas las culturas pueden ser comparables en tanto son poseedoras de sistemas de lenguaje que dan orden a la experiencia de los individuos y 
les proveen los significados para generar formas culturales complejas [Mukerji y Chudson, 1991: 18].

Clifford Geertz entiende la cultura no solo como el reflejo de lo social, sino también como la producción activa de significados [Mukerji y Chudson, 1991: 21). Las manifestaciones culturales pueden leerse como un texto, que no representa de manera homogénea a una determinada cultura, sino que más bien es un texto leído de maneras diversas por los miembros de esa cultura. La definición de Geertz más popularizada sobre la cultura entiende a la humanidad inmersa en redes de significación que ella mismo ha tejido. Pero la cultura o los sistemas culturales también representan un texto a ser interpretado por el antropólogo. Esta distinción plantea un giro de sentido, el llamado giro interpretativo, ya que lo producido por la ciencia antropológica no es una verdad absoluta sino una interpretación generada por un autor a partir de una descripción densa y profunda de las interacciones sociales sucedidas en ella [Mukerji y Chudson, 1991: 22].

Se debe recordar que tanto el estructuralismo como la teoría de la interpretación han sido parte de una constante reflexión crítica en el campo de la antropología, en la que tanto sus aspectos teóricos como sus métodos de investigación han sido desafiados por comentarios críticos. Estas discusiones han encaminado su desarrollo como disciplina. Para el antropólogo Johannes Fabian, aprehender a la cultura popular desde la antropología solo ha sido posible una vez que se ha ido más allá de las restricciones teóricas [del funcionalismo, el marxismo, el estructuralismo, etc.]. [1998: 17] La antropología posmoderna ha desafiado el entendimiento de las culturas como totalidades cerradas. Por ejemplo, James Clifford [1986] ha ubicado la invención del otro presente en la etnografía. Para el autor se hace necesario repensar la propia práctica antropológica como una construcción de las culturas mediada por el texto. Según el autor, la etnografía trata de la invención y no solo de la representación de la cultura. La etnografía, como herramienta de conocimiento y "autoridad" etnográfica, se encuentra situada entre poderosos sistemas de significación.

La antropología crítica también atacó la preferencia de la disciplina en la búsqueda de prácticas culturales puras, así como su fijación en el estudio del otro primitivo, y abrió la perspectiva para la investigación sobre la cultura popular contemporánea, antes dominio exclusivo de la sociología.

Para Johannes Fabian - quién desarrolló la mayor parte de sus investigaciones en África- la noción de cultura popular es legítima para conceptualizar ciertos tipos de praxis humana que el concepto de cultura por si solo tiende a ignorar o a desaparecer [Fabian, 1998: 1]. ¿Qué es lo no puede captar el concepto de cultura en su sentido antropológico? Para Fabian el modelo culturalista ignora lo que sucede con la cultura cuando esta deja de poder ser analizable como una totalidad pura. Si en las reflexiones disciplinarias hay una fascinación con la cultura estable, entonces la teoría resultante no es capaz de captar lo que no entra en esos parámetros [1998: 4]. La posición de Fabian con respecto a la cultura popular nos lleva a mirarla como un hecho histórico y contemporáneo a la ciencia que la estudia: la antropología [1998: 31].

Para el autor la cultura popular es una mezcla heterogénea de tradición y modernidad. Sin embargo, hay que partir de que tanto la tradición como la modernidad son parte de la misma temporalidad. Trasladando esa idea al presente estudio, hay que pensar que no se trata de que la tradición popular latinoamericana esté colocada en un pasado inmemorial- tradicional y se contamine con la presencia de elementos importados desde la globalidad. Más bien, de lo que se trata es de que distintos elementos vienen a convivir en un mismo tiempo. No se trata de un impacto de la modernidad en la tradición, sino de transformaciones culturales que se dan en procesos concretos [Fabian, 1998: 73-74] Parafraseando a Fabian: El estudio de la cultura popular puede ser pensado para redescubrir la libertad como una condición de sobrevivencia a través de la creatividad en situaciones que desde la mirada de la teoría cultural solo pueden ser vista como demasiado precarias para sostener nada más que imitaciones, semejanzas o caricaturas de la cultura [74].

La anterior concepción es importante para las manifestaciones estéticas populares en la contemporaneidad, ya que ubica una problemática presente al tratar de evaluar la producción cultural popular, su carácter intangible, su localización fuera de la oficialidad que trata de aprehenderla como folklore, su transformación constante, su carácter fragmentado y precario y, en muchos casos, la desaparición de sus prácticas creativas.

Al hablar de libertad, Johannes Fabian está pensando en las expresiones creativas urbanas de Zaire y cómo en el contexto de una sociedad poscolonial con una historia de explotación y fuertes exclusiones sociales se desarrollan expresiones que contrarrestan al poder. La explotación y la exclusión son también hechos latentes en la realidad latinoamericana; sin embargo, en su devenir histórico también ha habido manifestaciones de malestar y luchas populares que han contrarrestado el poder hegemónico. 
Es interesante pensar que tanto el carácter de explotación de los subalternos, como su capacidad de resistencia, han sido motivos de representación y apropiación por parte del arte moderno y contemporáneo.

Otra idea importante en la teoría de Fabian está en su noción sobre el lugar de la cultura popular. Si los estudios antropológicos clásicos ubicaban a lo popular en espacios territoriales delimitados, Fabian argumenta que a lo popular no se lo puede captar en lugares o espacios sino en los momentos de creación o de negación que es cuando se encuentra energizada; es decir, en los "momentos de libertad" (133). Como manifiestan Rowe y Schelling [1991], hay que considerar que la cultura popular tiene límites cambiantes. En ese sentido, es útil una movilidad de términos y conceptos. Para los autores los conceptos de conversión, resignificación y resemantización son apropiados para tratar el tema de la cultura popular [Rowe y Schelling, 1991: 26]. Hay que reparar en que el arte contemporáneo se relaciona con una cultura popular que no es estable, sino influenciada por componentes globales que son resemantizados de acuerdo a códigos locales. Una cultura popular que tampoco se encuentra en lugares delimitados, sino que se ubica en sitios dispersos.

Un acercamiento a la cultura popular necesariamente tiene que alejarse de su esencialización y romantización. No hay que olvidar que Fabian realiza su análisis sobre las manifestaciones creativas concretas de Zaire y, si bien es cierto que lo popular puede captarse en "los momentos de libertad", también está presente en manifestaciones de racismo, machismo, esencialismo, las cuales no pueden celebrarse acríticamente [Mukerji y Schudson, 1991: 35].

Para esta investigación también es necesario la utilización de conceptos que comprendan a la cultura popular como un elemento dinámico y con características contrahegemónicas que no le son inmanentes, sino que más bien se activan en determinadas circunstancias históricas. Ha sido superada la mirada a la cultura popular como en un ámbito separado de la cultura de élite. La teoría también ha logrado distanciarse de una visión folklorizada de lo popular, es decir, colocada como una entidad perteneciente a la tradición y opuesta a la modernidad. Para autores como Hall [1984] y Rowe y Schelling [1991] hay dos nociones clásicas de lo popular de las cuales es necesario distanciarse: la primera está dada por mirar los procesos culturales y sociales desde una perspectiva nostálgica que se concentra en las amenazas y contaminaciones que representa la industrialización. La segunda noción se relaciona en cambio con pensar a la cultura popular como algo producido por los medios masivos de comunicación y en control de la clase dominante. Esta apreciación ve a la cultura popular como una amenaza para la libertad y autodeterminación de la gente [estas ideas están presentes en la Escuela de Frankfurt Horkheimer, May y Adorno].

Una discusión que es importante por la influencia que ha tenido en la teoría sobre la cultura popular es la discusión de hegemonía propuesta por Gramsci. Cuando Johannes Fabian reflexiona que la fuerza de la cultura popular consiste en que se trata de un proceso en curso, en el que el poder es constantemente negado y reestablecido [1998: 133], podemos palpar de manera implícita que en sus ideas habita el concepto de hegemonía.

Este concepto ve el proceso de articulación de sentido común y dominación como algo que no es solo impuesto desde arriba, sino que es producto de luchas culturales; es decir, se trata de un proceso de dominación y resistencia que se va rearticulando históricamente. La hegemonía no se da por imposición violenta, sino por medio de la sutil generación de consensos que, aunque pretenden representar a la mayoría, son promulgados desde los grupos dominantes [Crehan, 2002: 182]. El consentimiento del dominado está implícito en esta relación, pero lo interesante de la concepción de hegemonía es que es posible el espacio para una reversión de lo dominante por medio de la generación de espacios de lucha contrahegemónicos. Kate Crehan enfatiza sobre la utilidad del concepto para debatir el concepto de cultura desde el punto de vista antropológico e introducir el tema de la inequidad y las relaciones de poder. Para la autora representa una forma de actualizar y volver a utilizar la categoría "clase" en la discusión sobre la cultura [189]. Considero que, para hablar de cultura popular, las discusiones de Gramsci son importantes porque introducen el tema del poder desde una perspectiva que no lo reduce a un problema económico. Si lo cultural está incluido por medio de la hegemonía es para pensar las constelaciones de poder que se manifiestan en tiempos y espacios específicos entre lo dominante y lo dominado [Crehan, 2002: 66]. Hay que pensar la hegemonía como un término fluido que lo que hace es nombrar las relaciones de poder que sustentan las desigualdades. De esta manera, para entender cómo el poder es producido y reproducido, se depende de la mirada a contextos específicos [101]. El contexto de hegemonía también es útil para pensar la relación entre arte contemporáneo y cultura popular. Aunque esta relación no se da necesariamente entre dominantes y dominados, en las propuestas de artistas 
contemporáneos que se apropian de lo popular se dan en muchos casos problemáticas relacionadas con el poder.

La noción de hegemonía también ha sido utilizada por los estudios culturales británicos. Hall [1984] y Williams [1987] han aportado al utilizar esta concepción para repensar la cultura popular [Traube, 1996: 133]. Así, cultura popular en los términos de Stuart Hall [1984] se relaciona directamente con la lucha cultural de los sectores subalternos frente a la dominación. La relación entre subordinados y dominantes es tomada por Hall como un aspecto dialéctico, en el sentido de que:

hay una lucha continua irregular y desigual, por parte de la cultura dominante, cuyo propósito es desorganizar y reorganizar constantemente la cultura popular; encerrar y confinar sus definiciones y formas dentro de una gama más completa de formas dominantes. Hay puntos de resistencia; hay también momentos desinhibición. Esta es la dialéctica de la lucha cultural. [Hall, 1984: 5]

Considero que el acercamiento de Hall es útil para mirar un aspecto de la cultura popular. Me da curiosidad, sin embargo, saber que sucede cuando la cultura popular se encuentra inhibida: ¿se está reorganizando para continuar la lucha, está aletargada por la influencia de los medios masivos? Me pregunto si esas formas cotidianas de acción [Roseberry, 2002] necesariamente se articulan en función de una reacción contra la cultura dominante. Por ejemplo, creo que los sectores populares actuales del Ecuador desarrollan prácticas sociales que no necesariamente están en contraposición a las elites. Decir que lo que acontece en un espacio de socialización como una cancha de fútbol o en un balneario como el del Tingo [Quito] tiene un carácter de resistencia es un ejercicio forzado, pero negar la riqueza cultural de estos espacios por no tener como componente central la lucha cultural lleva a un determinismo en que lo popular es pensado solamente como algo que se activa por acción de lo dominante, una explicación que llevaría a inferir que la gente no posee prácticas de socialización autogeneradas y producción de sentidos.

Lo que acontece en el espacio público de Quito, en la vida barrial y cotidiana, se relaciona con las nociones de carnaval, de la risa, de lo grotesco y del lenguaje de la plaza pública de Bajtin [2003]. La cultura popular está presente en las fiestas populares que, a pesar de la modernización, mantienen personajes tradicionales como los payasos y los diablos, los cuales, a su vez son semantizados con la incorporación de elementos de la cultura masiva.
En los partidos de fútbol barrial, que son lugares de socialización y consolidación de lazos; en los balnearios de domingo, repletos de gente, espacios para el goce y para la recreación de los vínculos familiares; y también en los mercados y ferias públicas en las que el comercio callejero trata de ganarle el pulso a las restricciones municipales. Lo popular está presente en un sinnúmero de sitios dispersos en los que [en palabras de Fabian] se energiza la cultura popular.

Consideró que los conceptos de Bajtin [2003] son de utilidad para la realidad quiteña y para un entendimiento de la posibilidad transgresora de la gente desde sus prácticas cotidianas. Para producir estas ideas, Bajtin abordó la obra de Rabelais para dar cuenta de cómo, en la edad media, en el carnaval y la plaza pública se articulaba un lenguaje que incluía a la risa y al cuerpo grotesco, que revertía las categorías de lo alto y lo bajo y planteaban en sí una resistencia y una contestación ante la dominación mediada por la seriedad de la cultura oficial. Hay que considerar que la obra de Bajtin es realizada en los años cuarenta, su reflexión, por lo tanto, tiene sus limitaciones en cuanto a una cierta romantización de la potencialidad transgresora de lo popular. Sin embargo, su literatura es importante porque abre el camino para un pensamiento cultural desde abajo, desde un entendimiento de la vida subalterna [Burke, 2008].

Una de las críticas que se le hace a Bajtin recae en su noción de que la cultura de la plaza pública estaría afuera de la cultura oficial y en contraposición a ella [Bajtin, 2003]. Stallybrass y White [1986: 16], critican la localización al margen de la cultura popular, debatiendo que la plaza pública es un lugar de intersección entre lo alto y lo bajo, y que atraviesa tanto lo económico como lo político. Para los autores, la resistencia y la oposición que la cultura popular puede hacer a la oficialidad no es una cualidad predeterminada de esta, es más bien algo que se activa bajo circunstancias específicas: por ejemplo, en los intentos de control de las manifestaciones populares. Por esto, las políticas del carnaval no pueden entenderse sin un acercamiento analítico a las coyunturas históricas específicas [16]. Los autores también resaltan el carácter reaccionario que la cultura popular puede tener en determinados momentos, aliándose al poder para atacar a los débiles [18]. Ponen como ejemplo de esta situación la quema de las brujas ${ }^{1}$

$1 \quad$ Pienso que en la historia del Ecuador se podrían rastrear muchos momentos en que la cultura popular ha manifestado su carácter de resistencia, pero también se 
Lo importante de los conceptos de hegemonía de Gramsci [Creham, 2002] y lenguaje de la plaza pública de Bajtin [Bajtin, 1998], y sobre todo las posteriores discusiones que como ideas desencadenaron, es que se alejan de otorgar un lugar estático a la cultura popular y ven el sentido de resistencia no como una esencia apriorística de lo popular sino algo que se activa en determinadas circunstancias históricas. Por esa misma línea de pensamiento, Johannes Fabian piensa que, al mirar a las condiciones históricas concretas de la cultura popular, ver los procesos sociales como si se tratara de una simple oposición entre dominados y dominantes no es suficiente [1998: 41]. Para este autor, tenemos que asumir que la cultura popular es seudomorfa, y tiene sus formas específicas dependiendo de las maneras en las que se articule el poder que debe resistir o acomodar. Considero que esta suma de conceptos permite pensar a la cultura popular, así como a las apropiaciones que el arte contemporáneo hace en torno a ella, como hechos históricos relacionados con un contexto.

\section{Lo popular en Latinoamérica}

En una reseña sobre las distintas aproximaciones sobre cultura popular, Fabian explora la significación que se le da geopolíticamente a cultura popular: hay que pensar que incluso en la actualidad no es lo mismo hablar de cultura popular en Europa y Estados Unidos que hacerlo en Latinoamérica [Fabian, 1997: 40].

¿Qué especificidad tiene en Latinoamérica lo popular? quizás una respuesta pueda encontrarse a partir de la lectura del trabajo analítico sobre la cultura popular en esa región por Rowe y Schelling [1991]. En un seguimiento histórico por la heterogeneidad de espacios latinoamericanos puede verse la fuerza de la cultura popular, su ligazón con lo étnico y su capacidad de organización y lucha. En un artículo posterior, Schelling [1996: 257) enuncia una frase que sintetiza la especificidad de la cultura popular en Latinoamérica: “[...] las culturas populares de Latinoamérica no son simples formas de folklore consignadas al pasado o versiones degradadas de la alta cultura o la industria cultural, sino una fuerza que estructura alternativas a las estructuras existentes de poder." Esta frase da

podrían encontrar hechos que demuestran lo contrario. Un ejemplo del carácter reaccionario de la cultura popular está presente en el arrastre y quema del presidente Eloy Alfaro: en ese momento la sociedad quiteña se alió a los intereses aristocráticos cercanos al Partido Conservador. cuenta de una característica intrínseca y propia de lo latinoamericano. Sin embargo, es necesario no olvidar que Latinoamérica contiene una heterogeneidad de modos de entender el mundo, así como una diversidad de procesos culturales, que son complejos y que están atravesados por relaciones de poder y correspondencias entre lo local y lo global. Frente a este panorama heterogéneo, dinámico y cambiante cabe hacerse la pregunta de si es válido entender la cultura popular de todo un continente a través de una localización geográfica como "lo latinoamericano". Consideró que una aproximación de este tipo no es de utilidad si está enfocada en la búsqueda de identidades esenciales. Sin embargo, hablar de una cultura popular latinoamericana es conveniente para hacer un ejercicio comparativo entre los distintos contextos. Además, ubicar el campo geográfico permite constatar el lugar poscolonial de Sudamérica y evidenciar los "momentos de libertad" [Fabian, 1998] que se han presentado en su historia.

Conceptos como culturas híbridas de Garcia Canclini [1990] y mestizaje [Kingman, 1999 y Serge Gruzisnki, 2002) son ideas que han permitido a los pensadores latinoamericanos reflexionar sobre las dinámicas culturales de la globalización y sobre la influencia de la cultura masiva internacional que se hace cada vez más latente en lo local. Estas aproximaciones interrogan críticamente alrededor del tema identitario, posibilitan dejar atrás la búsqueda de identidades esenciales basadas en supuestos valores nacionales o locales abstractos, superando así un entendimiento de los procesos contemporáneos de la globalización como homogeneizadores, para aprehenderlos como lo que son: procesos culturales complejos que tienen variadas formas de expresarse en los distintos contextos.

\section{Sistemas de clasificaciones y otorgación de valor a la cultura popular}

En el anterior acápite se hizo una revisión teórica para aprehender la complejidad del concepto de cultura popular. A partir de esa indagación se ubicaron ciertas definiciones que son de utilidad para entender la relación entre arte contemporáneo y cultura popular. La producción textual sobre cultura popular es considerable y las interpretaciones sobre cultura popular han ido variando a través del tiempo. Dentro del amplio campo de estudio ha habido teóricos que han reflexionado sobre los tópicos de la alta y la baja cultura, tratando de entender los distintos modos en que se construyeron esas categorías. Un ejemplo de esta línea de trabajo ha sido planteado por Bourdieu, a través de su concepto sobre la distinción, con el cual plantea cómo hay ciertas actividades y consumos estratificados como alta 
cultura, los cuales, luego de ser aprendidos y reproducidos a través del habitus, son los que diferencian y distinguen a un grupo social de otros. Como una categoría construida, la distinción opera entre las clases sociales por medio de una representación dada, no solo por las diferencias económicas sino también por los sutiles hábitos y los consumos culturales que diferencian a una clase de otra. No es el momento para detenerse en el concepto de distinción. Nombramos a Bourdieu porque su aproximación a la alta cultura da cuenta de su construcción histórica y su vínculo con desiguales relaciones de poder. Al igual que la alta cultura, la noción de que existe un arte erudito o culto y diferenciado de las otras producciones es parte de una construcción histórica.

El siguiente acápite se centrará en propuestas teóricas que reflexionan críticamente sobre la clasificación entre alta y baja cultura en el mundo del arte y sobre los mecanismos de asignación de valor a los objetos artísticos. Con la ayuda de James Clifford [1995], se ubicarán los sistemas de arte y cultura, a través de los cuales se asigna valor al arte no occidental. Su análisis, aunque centrado en el consumo de la cultura material "primitiva" en los museos y galerías del norte, es importante porque da cuenta de la arbitrariedad presente en la asignación de valor. Por medio de Ticio Escobar [2008] se reflexionará sobre la especificidad de la cultura popular latinoamericana y se interrogará sobre la utilidad de trasladar los conceptos del arte occidental al arte popular. Por medio de García Canclini [1989] se localizarán las transformaciones e influencias mutuas de lo culto y lo popular en el contexto de la globalización, así como la influencia, cada vez más determinante, de lo masivo.

James Clifford plantea que los procesos de recolección de cultura material no occidental han generado sistemas de arte-cultura, los cuales recolectan, clasifican y ordenan los objetos por medio de la asignación de valores culturales [científicos] o como obra de arte [estéticos] [2001: 265]. Las categorías de arte y cultura, o la asignación del valor artístico o cultural a un objeto, no es inmutable, es, más bien, intercambiable, como lo evidencia Clifford: los objetos africanos pasaron de ser fetiches aprehendidos como rarezas, a objetos de interés etnográfico, para luego ser considerados "obras de arte" altamente valoradas en el mercado del arte. ¿Pero cómo se le asigna el valor a un objeto? ¿De que depende que una pieza ingrese a ser parte de un sistema de colección y no de otro? ¿Cómo se da la mutación de un sistema a otro? Para Clifford

El sistema clasifica objetos y les asigna el valor relativo. Establece los "contextos" a los que pertenecen propiamente y entre los que circulan. [hay movimientos del sistema que] seleccionan artefactos de méritos y rareza perdurable, cuyo valor normalmente está avalado por un estatus cultural que se "desvanece" o por mecanismos de selección y asignación de precios del mercado del arte" [2001: 265 - 266].

El museo etnográfico y el museo de Bellas Artes han sido los lugares de acumulación de los objetos de la otredad no occidental. Lo paradójico, para Clifford, es que a partir de objetos seleccionados y exhibidos bajo una determinada narrativa se ha pretendido presentar la totalidad de una cultura.

Al Igual que James Clifford [2001], Ticio Escobar [2008, 1986] nos recuerda que lo artístico no es una cualidad intrínseca de un determinado objeto, sino que depende de la ubicación que se le otorga en determinadas circunstancias socioculturales [2008: 50]. Si Clifford reflexiona críticamente sobre los sistemas de arte y cultura como medios de asignar valor a los objetos en Occidente, Ticio Escobar está interesado en pensar sobre cómo operan en Latinoamérica las distinciones entre lo culto y lo popular. Clifford ubica dos sistemas que aprecian a los objetos no occidentales desde una perspectiva artística o etnográfica. Ticio Escobar, en cambio, se concentra en develar cómo ciertas categorías producidas en la teoría artística [el arte] y en la teoría social [el pueblo] son problemáticas - y por lo tanto tienen que ser discutidas- para reflexionar sobre la cultura material popular o, como Escobar prefiere nombrarla, el arte popular?

El análisis de Escobar es interesante como un intento de pensar la producción visual desde Latinoamérica. En ese sentido, el antropólogo se pregunta sobre la validez y vigencia de trasladar nociones de Occidente a nuestros contextos. En su pensamiento hay una búsqueda de entender el arte popular paraguayo, fuertemente ligado a lo ritual desde otra perspectiva a la impuesta por la teoría artística occidental. Escobar es de la opinión de que si se piensa al arte popular teniendo como parámetro de comparación los valores artísticos de Occidente, se lo termina colocando en un estatuto de arte menor o "como algo venido a menos", a través de esa mirada como balanza valorativa el arte popular carece de autonomía artística, originalidad y la producción individualizada de un genio

2 Ticio Escobar opta por llamar a la producción simbólica de la cultura popular "arte popular", ya que, a pesar de ser términos construidos en Occidente, sin la utilización de los mismos se coloca a lo popular en el terreno de lo inefable. 
artista $^{3}$. No se puede olvidar que las nociones dominantes de lo popular son construidas y tienden a mirarlo como anclado en el pasado e ingenuo, produciendo objetos no contemporáneos al nuestro. Escobar traslada las ideas [para el autor mitos] que dan trascendencia al arte occidental, ubicando que muchas de las características del arte moderno están también presentes en el arte popular. Al contrario de esa visión, su aproximación defiende la cualidad reflexiva histórica y contemporánea del arte popular, y observa que en mucha de la producción indígena coincide lo estético y lo poético [2008: 71]. En resumidas cuentas, defiende la diferencia como un sitio [o sitios] para repensar sobre la producción cultural popular.

García Canclini aporta con el concepto de puesta en escena de lo popular, esto es, la interpretación y puesta en circulación de contenidos de la cultura popular en el ámbito intelectual o artístico. El autor muestra cómo desde el siglo XVIII, ha habido un acercamiento folklorista a la cultura popular. Este enfoque de investigación fue trasladado por los intelectuales latinoamericanos como una forma de aprehender lo popular como lo tradicional, como lo anclado en el pasado [García Canclini, 1990: 200). Este autor critica frontalmente estos acercamientos argumentando que son incompatibles con la realidad y el estado actual de las ciencias sociales [200]. Ahora se piensa que las culturas populares "se han desarrollado transformándose". Para el autor no se trata de: "conservar y rescatar tradiciones supuestamente inalteradas. Se trata de preguntarnos cómo se están transformando, cómo interactúan con las fuerzas de la modernidad." [203]

Los estudios de cultura popular tienen que tener en cuenta los cruces culturales acaecidos a partir de la globalización, considerando que provocan una "reestructuración radical de los vínculos entre lo tradicional y lo moderno, lo popular y lo culto, lo local y lo extranjero" [223]. El planteamiento de García Canclini es que se da una difuminación de las fronteras entre lo culto y lo popular a través de la incorporación de lo masivo. Para el autor, la globalización conlleva una difuminación de los consumos: productos antes asignados a la esfera de la alta cultura son traspasadas a cultura popular y viceversa. El autor ubica que en la época actual la artesanía también se nutre de referentes globales [226], por lo tanto, pensar un acercamiento que localice a lo popular solo en lo rural o en lo tradicional ya no tiene sentido.

En las prácticas artísticas contemporáneas producidas en Latinoamérica lo popular ha sido puesto en escena de muchas

3 La discusión a estos mitos del arte occidental se puede encontrar en la teoría artística estadounidense a través del pensamiento de Rosalind Krauss [2006]

Craig Owens (1994) y Hal Foster [1996] entre otros. maneras. Hay acercamientos que han comprendido el carácter híbrido de la cultura popular; otros que han romantizado la visualidad de sus productos visuales y otras prácticas artísticas que han ido más allá de la representación y plantean procesos de diálogo, construcción conjunta de significados e involucramiento en procesos políticos específicos. Los debates presentados en este artículo son insumos teóricos útiles para pensar y problematizar propuestas artísticas contemporáneas que se relacionan con la cultura popular.

\section{Conclusiones}

El presente artículo ha situado ciertos conceptos que, aunque no han sido pensados para tratar específicamente sobre la cultura popular, son claves para comprender sus dinámicas. Entre estos, está la noción de hegemonía de Gramsci; los términos campo y distinción de Bourdieu y la idea de sistemas de arte y cultura de James Clifford. Se trata de conceptos útiles para pensar la cultura popular como un espacio de cruces y fronteras en el que entran en juego distintas fuerzas. Si asumimos la noción de hegemonía propuesta por Gramsci, veremos el poder como algo que no es solo impuesto desde arriba, sino que es producto de relaciones culturales múltiples entre las clases, es decir, como algo generador tanto de situaciones de fuerza como de consensos. Esto solo puede entenderse históricamente como parte de luchas sociales y culturales y de prácticas cotidianas de representación y resignificación. La propia noción de hibridación podría ser analizada desde esta perspectiva: no como un encuentro casual de elementos culturales sino como parte de campos de fuerzas. Pero, además, la perspectiva de Gramsci introduce el tema del poder cultural que va más allá de lo puramente económico. Estas teorías dan cuenta de lo popular en un sentido fluido, de producción de significados en medio de disputas y relaciones constantes; aportan en la reflexión sobre lo popular [y sus manifestaciones estéticas] como algo que se redefine constantemente en relación con la cultura hegemónica, incorpora elementos de la cultura de masas y de las formas culturales de las elites y se presenta bajo la forma de prácticas de libertad.

Aunque no se ha analizado directamente la relación entre arte y manifestaciones estéticas populares, las teorías revisadas en este documento aportan como herramientas conceptuales para reflexionar en torno a las correspondencias entre prácticas artísticas específicas y cultura popular. Del mismo modo, como la cultura popular está sujeta a distintas resignificaciones, la producción artística contemporánea en su vertiente más crítica se inscribe dentro de una relación dialógica, abierta y creativa con la popular. No obstante, estas cualidades no pueden ser esencializadas ya que cada práctica artística contemporánea que se relacione 
con la cultura popular desde la representación y/o el diálogo, tiene que ser analizada de manera específica. En conclusión, las teorías reseñadas en este artículo pueden ser herramientas conceptuales útiles para ese cometido.

\section{Referencias}

Bajtin, M. [2003]. La cultura popular en la edad media y en el renacimiento: el contexto de François Rabelais.Madrid: Alianza Editorial.

Bourdieu, P. [1997]. Razones prácticas. Sobre la teoría de la acción. Barcelona: Anagrama.

Burke, P. [2008). "Cuarenta a-os despúes”. En Bajtín y la historia de la cultura popular: cuarenta a-os de debate. Cantabria: Universidad de Cantabria.

Burke, P.(1984). "El Descubrimiento de la Cultura Popular". En Historia Popular y teoría socialista. Raphael Samuel [Ed.): 78-92. Barcelona: Crítica.

Cadena, Marisol de la [2004]. Indígenas Mestizos: Raza y Cultura en el Cusco. Lima: Instituto.

\section{PMCid:PMC3851403}

Clifford, J. [2003). On the Edges of Anthropology [Interviews] Chicago, Pricly Paradigm Press

Clifford, J.(1995). Dilemas de la cultura, Barcelona: Gedisa.

Clifford, J. y Marcus G. [1986]. Writing Culture: The Poetics and Politics of Ethnography. Los Angeles: University of California Press.

Crehan K. [२ОО२] Gramsci, Culture and Anthropology. California: University of California Press.

Elias, N. [1986] El proceso civilizatorio - México: FCE.

Escobar, T. [2008 [1986]]. El mito del arte y el mito del pueblo. Santiago de Chile: Metales Pesados.

Escobar, T. [1996). "Issues in Popular Art". En Beyond The Fantastic [Gerardo Mosquera] ed. London: MIT Press.

Fabian, Johannes [1998). Anthropology and Popular Culture. Charlottesville: University Press of Virginia.

Foster, H. [1996]. "The Artist as Etnographer”. En The Return of the Real. The Avant-garde to the End of the Century. Massachusetts Institute of Technology.

García Canclini, N. [2002 [ 1982]]. Las culturas populares en el capitalismo. México.

García Canclini, N.(1996]. "Modernity after Postmodernity”. En Beyond the Fantastic [Gerardo Mosquera]. London: MIT Press.

Gramsci, A. (2002). From the 'Prison Notebooks'. Daedalus.

Gruzinski, S. [2002). The Mestizo Mind: The Intellectual Dynamics of Colonization and Globalization. New York: Routledge.

Hall, S. [1984]. "Notas sobre la desconstrucción de 'lo popular"'. En Historia popular y teoría socialista [Ralph Samuel ed.] Crítica: Barcelona.

Horkheimer, M. y Adorno, T. [1988]. Dialéctica del iluminismo. Buenos Aires: Sudamericana.

Kingman Garcés, E.; Ton Salman y Anke Van Dam [1999]. "Las culturas urbanas en América Latina y los Andes: lo culto y lo popular, lo local y lo global, lo híbrido y lo mestizo".En Antigua modernidad y memoria del presente: culturas urbanas e identidad. Salman Ton y Kingman Eduardo ed. Quito: FLACSO - Sede Ecuador.

Krauss, R. [2006]. La originalidad de la vanguardia y otros mitos modernos. Alianza.

Mukerji y Chudson [1991]. Rethinking Popular Culture: Contemporary Perspectives in Cultural Studies. University of California Press.

Owens, C. [1994]. Beyond Recognition: Representation, Power, and Culture. Berkeley: University of California Press.

Salman, T. [1996]. "The Locus of Dispersion: Studying Latin American Popular Culture in the 1990s". En The Legacy of the Disinherited: Popular ^ Culture in Latin America : Modernity, Globalization, Hybridity and Authenticity, Tom Salman [Comp]: Amsterdam: Centro de Estudios y Documentación Latinoamericanos [CEDLA]

PMCid:PMC2074546

Rowe W. y V. Schelling [1993]. Memoria y modernidad: cultura popular en América Latina. Grijalbo.

Stallybrass, P. y A. White. [1986]. The Politics and Poetics of Transgression. London: Methuen.

Traube E G. (1996). “The Popular' in American Culture”. En Annual Review of Anthropology, Vol. 25], pp. 127-151.

https:/ / doi.org/10.1146/annurev.anthro.25.1.127

Williams R. [1997]. La política del modernismo. Buenos Aires: Manantial. 